\title{
ANÁLISE COMPARATIVA DOS CURSOS DE GRADUAÇÃO EM ADMINISTRAÇÃO NA ALEMANHA, NO BRASIL E NOS ESTADOS UNIDOS DA AMÉRICA
}

DIFFERENCES OF THE UNDERGRADUATE COURSES OF ADMINISTRATION IN GERMANY, BRAZIL AND UNITED STATES OF AMERICA

Recebido 09-10-2012 Aceito 21-02-2013

\author{
Andreas Dittmar Weise \\ Juliane do Nascimento de Quadros ${ }^{2}$ \\ Rudimar Antunes da Rocha ${ }^{3}$ \\ Andréa Cristina Trierweiller ${ }^{4}$ \\ Blênio Cezar Severo Peixe ${ }^{5}$ \\ Jaqueline Dill Barcellos ${ }^{6}$
}

\section{RESUMO}

O desenvolvimento de um país está estritamente ligado ao seu sistema de educação. Dessa forma, o objetivo deste artigo é apresentar os métodos adotados para seleção, avaliação e estrutura curricular dos cursos de administração na Alemanha, no Brasil e nos Estados Unidos da América (EUA). Para isso, realizou-se uma pesquisa bibliográfica nos sites do Ministério da Educação e das Universidades desses países. Observou-se que o curso apresenta diferentes habilitações quanto à estrutura curricular nos países estudados. Com isso, verificou-se que os desafios das universidades estão relacionados à conformidade da estrutura curricular com as cobranças do mercado, já que se busca a adaptação às necessidades da economia e a rápida adequação às mudanças constantes dos cenários.

Palavras-chave: Sistema Educacional, Curso de administração, Seleção para o curso superior, Estrutura curricular.

${ }^{1}$ Possui graduação e mestrado em Industrial-Engineering and Management pela Universität Leipzig e doutorado em Engenharia Civil pela Universidade Federal de Santa Catarina - UFSC. Atualmente é professor adjunto na Universidade Federal de Santa Maria - UFSM. Santa Maria, Rio Grande do Sul - Brasil. E-mail: mail@adweise.de.

${ }^{2}$ Possui graduação em Administração pela Universidade Federal de Santa Maria - UFSM, mestrado em Engenharia de Produção pela Universidade Federal de Santa Maria - UFSM. Atualmente é professora na Faculdade Avantis e no Instituto Federal de Santa Catarina IFSC. Florianópolis, Santa Catarina, Brasil. E-mail: jullynq@hotmail.com.

${ }^{3}$ Possui graduação em Administração pela Universidade Federal de Santa Maria - UFSM, mestrado em Administração pela Universidade Federal de Santa Catarina - UFSC, doutorado em Engenharia de Produção pela Universidade Federal de Santa Catarina UFSM, pós-doutorado em Administração pela Universidade do Minho. Atualmente é professor na Universidade Federal de Santa Catarina - UFSC. Florianópolis, Santa Catarina, Brasil. E-mail: rrudimar@hotmail.com.

${ }^{4}$ Possui graduação em Administração pela Universidade de Santa Catarina - UFSC, mestrado e doutorado em Engenharia de Produção pela Universidade Federal de Santa Catarina - UFSC. Atualmente é pós-doutorando em Engenharia de Produção pela Universidade Federal de Santa Catarina - UFSC. Florianópolis, Santa Catarina, Brasil. E-mail: andreatri@gmail.com.

${ }^{5}$ Possui graduação em Ciências Contábeis pela Universidade Federal do Paraná - UFPR, mestrado em Ciências Contábeis pela Universidade do Rio de Janeiro - UERJ, doutorado em Ciências Empresarias pela Universidade do Museu Social Argentino - UMSA, doutorado em Engenharia de Produção pela Universidade Federal de Santa Catarina - UFSC. Atualmente é professor adjunto na Universidade Federal do Paraná - UFPR. Curitiba, Paraná, Brasil. E-mail: blenio@ufpr.br.

${ }^{6}$ Faculdade Anhanguera de Passo Fundo. Passo Fundo, Rio Grande do Sul, Brasil. E-mail: jadi_q@ @hotmail.com 


\section{ABSTRACT}

The development of a country is closely linked to its education system. Thus the aim of this article is to present the methods adopted for selection, evaluation and curriculum of the courses of administration in Germany, Brazil and United States of America (USA). This study was conducted through a literature search, where were consulted websites of the Ministry of Education and universities of these countries that served as a reference for this research. The focus of this article is the comparison of administration courses in these three countries, which were explored aspects of the environment that has interaction with studied fact, it was used for the case study. It was made a critical analysis of the material collected, with the limitations of geographical character, because was approached the administration course in only three countries. It was observed that the course presents different qualifications as the curricular structure in the studied countries. Thus, it was found that the universities have the challenges related to compliance of the curricular structure with charges of the market, where it seeks to adapt to the needs of the economy and rapid adaptation to changing scenarios.

Keywords: Educational System, Administration course, Selection for the higher education course, Curricular structure.

\section{INTRODUÇÃO}

Estudos na área de administração podem aprimorar o entendimento sobre o indivíduo como parte integrante na sociedade, já que, por meio do ensino adequado, é possível gerar novos negócios que proporcionem o desenvolvimento socioeconômico. O papel da universidade é propiciar um ambiente educacional que desenvolva um profissional mais humano, crítico e inovador.

A Alemanha, o Brasil e os Estados Unidos da América (EUA) exibem diferentes evoluções em seus sistemas educacionais. Especificamente quanto ao curso de administração, esses países apresentam perfis distintos. Desde o século passado, a administração era estudada nos EUA; o primeiro curso de que se têm notícias foi criado pela Wharton School, em 1881. Na Alemanha, na década de 40, o curso surge como "centros de gestão" na Badener Unternehmergesprâche (MAURíCIO, 2004; CAMPELO, 2011). No Brasil, em 1902, a escola Álvaro Penteado, no Rio de Janeiro, e a Academia de Comércio, em São Paulo, já ministravam a administração; no entanto, não havia regulamentação para sua execução (NICOLINI, 2003 apud OLIVEIRA, 2007). Após a criação do Ministério da Educação, em 1931, órgão responsável pela regularização do ensino no país, foi criada a Escola Superior de Administração de Negócios, em São Paulo, e a Fundação Getulio Vargas (FGV), no Distrito Federal, também na década de 40 (OLIVEIRA, 2007).

Na Alemanha e nos EUA, os cursos de administração possuem ampla tradição nas universidades. Nos EUA, os cursos de administração apresentam particularidades em comparação ao Brasil e à Alemanha, sendo reconhecidos pela conquista de variados prêmios e pelos altos investimentos que são feitos até mesmo por seus ex-alunos. Já no Brasil, por ser um país em desenvolvimento, as universidades não têm muita tradição, embora o sistema de educação tenha apresentado um significativo crescimento devido a investimentos referentes ao Plano de Aceleração do Crescimento, que tem com um dos objetivos a expansão das universidades.

Com base nisso, este artigo busca descrever os métodos adotados por cada um desses países para seleção de alunos do curso de administração, bem como a estrutura curricular, a carga horária e as diferentes titulações que o curso possibilita. 


\section{METODOLOGIA}

O presente estudo caracteriza-se, quanto aos fins, como bibliográfico e descritivo. Foram consultados sites especializados das universidades públicas e dos Ministérios de Educação da Alemanha, do Brasil e dos EUA (VERGARA, 2010). A escolha dos países aconteceu pelo fato de que um dos autores é descendente da Alemanha e os outros são do Brasil. A escolha por aprofundar os estudos sobre esse tema foi devido ao interesse em contribuir ao desenvolvimento dos cursos de administração no Brasil, tendo como comparação os cursos da Alemanha e dos EUA, que são considerados tradicionais no ensino em administração.

Quanto classificação descritiva, Vergara (2010, p. 45) afirma que esta "expõe variáveis de determinada população ou de determinado fenômeno", sem o compromisso de explicá-lo, embora sirva de base para tal explicação. Quanto aos meios, este trabalho pode ser definido como um estudo de multi-casos, pois o foco é analisar os Programas dos cursos de graduação em administração, sendo exploradas as informações do ambiente que interagem com o fenômeno estudado (VERGARA, 2010).

Esta pesquisa aconteceu em três fases, conforme a Figura 1. Na primeira fase, foi realizada a coleta de dados secundários por meio de levantamento documental e bibliográfico. Segundo Lakatos e Marconi (2010), a pesquisa bibliográfica propícia o exame de um tema sob um novo enfoque ou abordagem. Dessa forma, os dados têm como origem fontes secundárias, as quais, para Lakatos e Marconi (2010), permitem a realização de estudos que possibilitam selecionar um tema, conforme as aptidões do pesquisador.

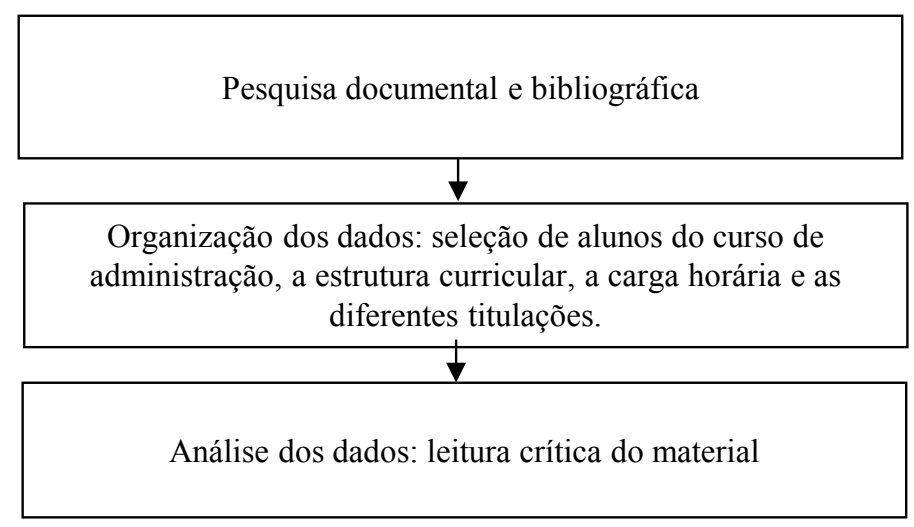

Figura 1 - Fases da pesquisa.

A organização dos dados ocorreu com base na intenção de descrever os métodos adotados por cada um desses países para seleção de alunos do curso de administração, a estrutura curricular, a carga horária do curso e as diferentes titulações permitidas por ele.

Quanto ao tratamento e à análise dos dados, procedeu-se a uma leitura crítica do material coletado ao longo do período compreendido entre janeiro a agosto de 2011, procurando identificar as principais semelhanças e diferenças entre os cursos dos três países estudados. 


\section{ANÁLISE DOS RESULTADOS}

\subsection{Alemanha}

A Alemanha possui um sistema de controle que acompanha os alunos durante sua caminhada educacional, premiando aqueles que se destacaram com a oportunidade de continuar seus estudos sem custos.

\subsubsection{Sistema de ingresso na universidade}

A educação fundamental, a partir dos sete anos, é obrigatória na Alemanha, sendo disponibilizada gratuitamente para toda a população. As opções de ingresso na universidade têm início já no ensino básico com a escola Gymnasium, que pode ser concluída em doze ou treze anos (HU, 2004). Ao término do Ginásio, os alunos passam por uma avaliação para entrar na universidade (HU, 2004). Aqueles que obtiverem as melhores notas concorrem a uma vaga na universidade. Porém, apenas os melhores do Gymnasium conseguem uma vaga, pois essas são limitadas.

\subsubsection{Tipos de ensino de administração nas universidades}

A educação na Alemanha é dependente da atuação do governo (ALEMANHA, GRUNDGESETZ, 2006). Conforme a Figura 2, existem três modelos de universidade: Universität, Fachhochschule e Berufsakademie. As Universtäten são consideradas as melhores no ensino de administração na Alemanha (UNIVERSITÄT LEIPZIG, 2012), pois oferecem um ensino mais completo. A Berufakademie é de caráter bastante prático, sendo quase equivalente ao tecnólogo no Brasil. Aos seus alunos é conferido o Diploma Alemão (é uma titulação antiga que vigorou até a entrada do processo de Bolonha, o qual obrigou as universidades alemãs a se adaptarem a um novo sistema) e o Bachelor of Arts (B.A.), Bachelor of Science (B.Sc.) e Master of Science (M.Sc.). Para custear os estudos, o aluno tem acesso ao crédito educativo chamado de Bundesausbildungsförderungsgesetz (Lei de promoção da formação profissional) (BAFÖG, 2007).

\subsubsection{Universität}

Como se pode observar na Figura 2, os alunos que cursam as Universitäten possuem a possibilidade de continuar seus estudos. Outra vantagem dessa universidade é que apenas os M.Sc. (duração de 4 semestres) da Universität podem fazer um doutorado. O B.Sc. tem duração média de 6 semestres, sendo composto de módulos. O aluno precisa fazer ainda um estágio de 12 semanas. Para aprovação do aluno, é necessário alcançar 180 pontos do European Credit Transfer System (ECTS, 2011), o que corresponde a um trabalho de 5.400 horas/aula (HU, 2004). 


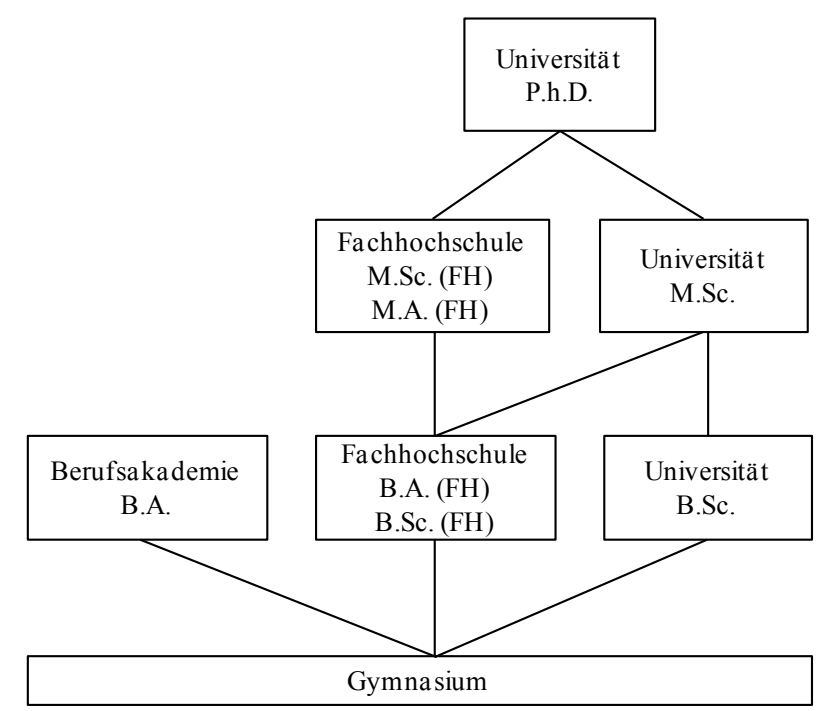

Figura 2 - Tipos de Universidades e Desenvolvimento Estudantil.

\subsubsection{Fachhochschule}

Para ingresso na Fachhochschule, é necessário cursar 12 semanas de estágio (480 horas) em uma empresa (FH TRIER, 2007). A duração do curso pode variar de 6 a 8 semestres. Com 8 semestres, o aluno da Fachhochschule obtém o título de B.Sc. (FH HANNOVER, 2007) e, com 6 semestres, recebe o título de B.A. (FH TRIER, 2011).

Nesse modelo de universidade, a aprendizagem está focada na administração geral, mas há a opção de estudar áreas específicas, como Banking and Finance ou International Business and Marketing. Para obtenção do título B.Sc., o aluno terá seus estudos divididos em duas partes: a primeira parte é constituída de 3 semestres, que acaba com a pré-prova, e a segunda parte é de 5 semestres, que termina com as provas de bacharelado (FH HANNOVER, 2007). É necessário efetuar um estudo de caso ou projeto administrativo durante 3 meses, em que o aluno irá ingressar em uma organização para colocar em prática os conhecimentos adquiridos durante o curso (FH HANNOVER, 2007).

O curso que emite o título de B.A. é formado por módulos. Estudam-se os fundamentos gerais, com base nas disciplinas respectivas aos conhecimentos específicos da área. Outras disciplinas são escolhidas conforme o interesse do aluno a fim de complementar sua carga horária. Para conclusão, uma monografia deve ser entregue (FH TRIER, 2011).

\subsubsection{Berufsakademie}

O foco da Berufakademie está relacionado ao conhecimento teórico aliado à prática empresarial. Com duração de 6 semestres (BA STUTTGART, 2011), esse método é realizado por meio da permanência do aluno na universidade em um turno e na empresa em outro.

Ainda, é exigida a troca de departamento a cada três meses, ampliando, assim, os conhecimentos nas variadas áreas administrativas (BA STUTTGART, 2010). Nesse sistema, o título que o aluno recebe ao término é Bachelor of Arts (with Honours) (BA STUTTGART, 2011). Porém, essa titulação não dá o direito de fazer cursos de pós-graduação na Alemanha. Há uma variedade de alternativas de estudos nessa universidade, tais como: economia de construção, marketing de serviços, mídias digitais, Facility Management, seguro e gestão imobiliária. 


\subsubsection{Estrutura curricular}

A estrutura curricular oferecida pela universidade na Alemanha, os créditos exigidos e a obrigatoriedade em fazer cada disciplina estão demonstrados nos quadros a seguir. A estrutura curricular do curso de administração de uma Universität é apresentado com base na Universität Leipzig (Quadro 1), que conta com uma carga horário de 180 Sistema europeu de transferência de créditos (European Transfer Credit System - ETCS).

\begin{tabular}{|c|c|c|c|c|c|c|c|c|}
\hline Disciplina & Tipo & 1 & 2 & 3 & 4 & 5 & 6 & Total \\
\hline Fundamentos de administração & Obrigatório & 5 & & & & & & 5 \\
\hline Matemática & Obrigatório & 5 & 5 & & & & & 10 \\
\hline Contabilidade & Obrigatório & 5 & & & & & & 5 \\
\hline Fundamentos de informática & Obrigatório & 5 & 5 & & & & & 10 \\
\hline Contabilidade gerencial & Obrigatório & & 10 & & & & & 10 \\
\hline Direito civil e público & Obrigatório & 5 & & & & & & 5 \\
\hline Direito das sociedades e lei comercial & Obrigatório & & 5 & & & & & 5 \\
\hline Microeconomia & Obrigatório & & 10 & & & & & 10 \\
\hline Macroeconomia & Obrigatório & & & 10 & & & & 10 \\
\hline Estatística & Obrigatório & & & 10 & & & & 10 \\
\hline Marketing e serviços & Obrigatório & & & 10 & & & & 10 \\
\hline Estágio & Obrigatório & & & & 5 & 5 & & 10 \\
\hline Estágio de qualificação da área & Obrigatório & & & & 5 & 5 & & 10 \\
\hline Econometria & Obrigatório & & & & 10 & & & 10 \\
\hline Análise de Investimento e Impostos & Obrigatório & & & & 10 & & & 10 \\
\hline País e Economia & Obrigatório & & & & & & 10 & 10 \\
\hline Língua estrangeira de negócios $1 \mathrm{X}$ & De escolha & & & & & & & 10 \\
\hline Língua estrangeira de negócios $2 \mathrm{X}$ & (30 ETCS) & & & & & & & 10 \\
\hline Cálculo de economia & & & & & & & & 10 \\
\hline $\begin{array}{l}\text { Pensar, Aprender, Solução de problemas e pes- } \\
\text { quisa }\end{array}$ & & & & & & & & 10 \\
\hline Relações internacionais & & & & & & & & 10 \\
\hline Logística e distribuição & & & & & & & & 10 \\
\hline Estágio 2 & & & & & & & & 10 \\
\hline Gerenciamento de empresa & & & & & & & & 10 \\
\hline Gestão de Seguros & & & & & & & & 10 \\
\hline Teoria econômica e ética & & & & & & & & 10 \\
\hline Teoria de jogos & & & & & & & & 10 \\
\hline Gestão e economia de inovação & & & & & & & & 10 \\
\hline Planejamento de infraestrutura & & & & & & & & 10 \\
\hline Inovação em serviços & & & & & & & & 10 \\
\hline Gestão pública & & & & & & & & 10 \\
\hline Pesquisa Operacional & & & & & & & & 10 \\
\hline Plano de negócios & & & & & & & & 10 \\
\hline Teoria monetária & & & & & & & & 10 \\
\hline Finanças & & & & & & & & 10 \\
\hline Gestão imobiliária & & & & & & & & 10 \\
\hline Desenvolvimento da cidade & & & & & & & & 10 \\
\hline Gestão ambiental & & & & & & & & 10 \\
\hline Custos de produção & & & & & & & & 10 \\
\hline Gestão energética & & & & & & & & 10 \\
\hline Economia bancária & & & & & & & & 10 \\
\hline Gestão de serviços & & & & & & & & 10 \\
\hline Seminário de diploma & Obrigatório & & & & & & 10 & 10 \\
\hline
\end{tabular}

Quadro 1 - Estrutura curricular de administração na Alemanha - Universität Leipzig.

Fonte: Universität Leipzig (2011). 
A Fachhochschule já tem um currículo um pouco diferente (154 ETCS), conforme Quadro 2.

\begin{tabular}{|c|c|c|c|c|c|c|c|c|c|c|}
\hline \multirow[b]{2}{*}{ Disciplina } & \multirow[t]{2}{*}{ Tipo } & \multicolumn{4}{|c|}{$\begin{array}{l}\text { Estudo básico } \\
\text { (horas de aula) }\end{array}$} & \multicolumn{4}{|c|}{$\begin{array}{c}\text { Estudos } \\
\text { principais } \\
\text { (horas de aula) }\end{array}$} & \multirow[t]{2}{*}{ Total } \\
\hline & & 1 & 2 & 3 & 4 & 5 & 6 & 7 & 8 & \\
\hline Fundamentos de administração & Obrigatório & 4 & & & & & & & & 4 \\
\hline Matemática & Obrigatório & 4 & & & & & & & & 4 \\
\hline Contabilidade & Obrigatório & 4 & & & & & & & & 4 \\
\hline Fundamentos de informática & Obrigatório & 4 & 2 & & & & & & & 6 \\
\hline Fundamentos de balanço & Obrigatório & & 2 & & & & & & & 2 \\
\hline Contabilidade gerencial & Obrigatório & & 4 & & & & & & & 4 \\
\hline Direito 1 & Obrigatório & 4 & 2 & & & & & & & 6 \\
\hline Direito 2 & Obrigatório & & & & 4 & 4 & & & & 8 \\
\hline Economia 1 & Obrigatório & 4 & 2 & & & & & & & 6 \\
\hline Economia 2 & Obrigatório & & & 4 & 4 & & & & & 8 \\
\hline Estatística & Obrigatório & & 4 & 4 & & & & & & 8 \\
\hline Língua estrangeira de negócios & Obrigatório & 4 & 2 & 2 & & & & & & 8 \\
\hline Marketing & Obrigatório & & 2 & 2 & & & & & & 4 \\
\hline $\begin{array}{l}\text { Administração da produção e de equi- } \\
\text { pamentos }\end{array}$ & Obrigatório & & 2 & 2 & & & & & & 4 \\
\hline Logística/cadeia de suprimentos & Obrigatório & & 2 & 2 & & & & & & 4 \\
\hline Recursos Humanos & Obrigatório & & 2 & 2 & & & & & & 4 \\
\hline Gerência empresarial & Obrigatório & & & 2 & 2 & & & & & 4 \\
\hline Informática de negócios & Obrigatório & & & 2 & 2 & & & & & 4 \\
\hline Análise de Investimento & Obrigatório & & & 2 & 2 & & & & & 4 \\
\hline Controladoria & Obrigatório & & & 2 & 2 & & & & & 4 \\
\hline Impostos & Obrigatório & & & 2 & 2 & & & & & 4 \\
\hline Pesquisa Operacional & Obrigatório & & & & 4 & 2 & & & & 6 \\
\hline $\begin{array}{l}\text { Estudos gerais (é necessário fazer du- } \\
\text { rante o estudo principal) }\end{array}$ & Obrigatório & & & & 2 & & & & & 2 \\
\hline Treinamento de comunicação e prática & Obrigatório & & & & & & 4 & & & 4 \\
\hline Foco do estudo (deve escolher 3 de 7) & $\begin{array}{l}\text { Obrigatório } \\
\text { de escolhia }\end{array}$ & & & & & 12 & & 12 & 12 & 36 \\
\hline \multicolumn{11}{|l|}{ - Ciências Bancárias } \\
\hline \multicolumn{11}{|l|}{ - Marketing/Sistema de feiras } \\
\hline \multicolumn{11}{|l|}{ - Informática de negócios } \\
\hline \multicolumn{11}{|l|}{$\begin{array}{l}\text { - Recursos humanos/desenvolvimento } \\
\text { de RH }\end{array}$} \\
\hline \multicolumn{11}{|l|}{ - Controladoria/contabilidade } \\
\hline \multicolumn{11}{|l|}{ - Auditória/Impostos } \\
\hline \multicolumn{11}{|l|}{$\begin{array}{l}\text { - Administração da Produção/Logísti- } \\
\text { ca/Materiais }\end{array}$} \\
\hline \multirow[t]{2}{*}{ Seminário de diploma } & Obrigatório & & & & & & & & 2 & 2 \\
\hline & & 28 & 26 & 28 & 24 & 18 & 4 & 12 & 14 & 154 \\
\hline
\end{tabular}

Quadro 2 - Estrutura curricular de Administração na Alemanha -Fachhochschule Leipzig.

Fonte: HOCHSCHULE FÜR TECHNIK, WIRTSCHAFT UND KULTUR (2012).

Além destas disciplinas, o aluno deve fazer um estágio prático com duração de pelo menos 20 semanas na área de atuação profissional (HOCHSCHULE FÜR TECHNIK, WIRTSCHAFT UND KULTUR, 2012). O currículo da Berufsakademie Dresden tem uma carga menor que o da Fachhoschule devido ao caráter mais prático do curso. 


\subsubsection{Avaliação}

A frequência do aluno nas disciplinas não é controlada. Muitas vezes, o professor recomenda a bibliografia e ministra certo número de aulas. As avaliações podem ser feitas de diversas formas: escrita, oral, trabalhos em casa, estudo de caso, entre outros. Além disso, não é necessário que o conteúdo das avaliações corresponda somente àquele mostrado pelo professor em sala de aula. Na maioria dos casos, os alunos possuem o direito de fazer uma prova até três vezes para a mesma disciplina, que acontecem ao final de cada semestre. Caso o aluno não cumpra essa regra, ele perderá o direito de estudar no curso (LUDWIG-MAXIMILANS-UNIVERSITÄT MÜNCHEN, 2011).

\subsection{ESTADOS UNIDOS DA AMÉRICA}

Nos Estados Unidos, a educação é um assunto regulado de modo diferente por cada estado. $O$ tempo de duração da escola varia de 9 a 13 anos. As decisões são tomadas no distrito de cada escola. Outro fator que torna complexo o sistema de estudo norte americano é a variedade de instituições privadas. Além disso, não há diferenciação horizontal na Elemantary School entre os alunos com maior ou menor desempenho.

\subsubsection{Ingresso na universidade}

O aluno deve fazer a High School (conhecida também como Senior High School ou Combined Junior Senior High School) (NCES, 2011), como demonstrado na Figura 3.

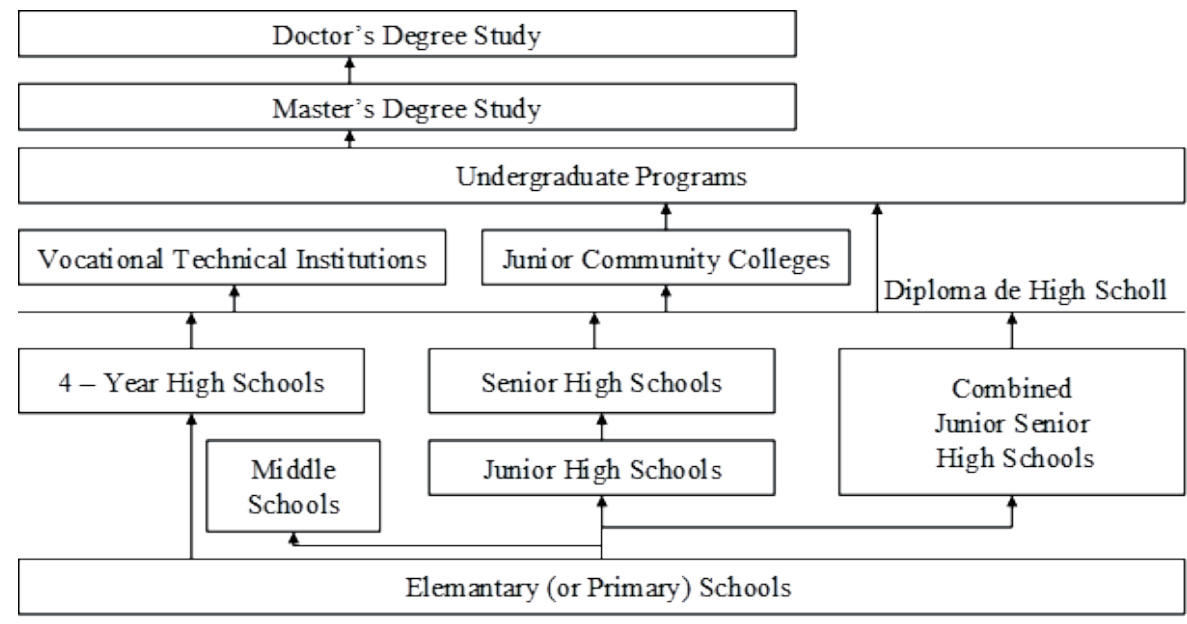

Figura 3 - Estrutura de educação nos EUA.

Fonte: NCES - National Center for Education Statistics (2011).

\subsubsection{Bachelor of Business Administration e Bachelor of Science in Business Administration}

Há dois bacharelados nos EUA: o Bachelor of Business Administration (BBA) e o Bachelor of Science in Business Administration (BSBA). Grande parte das universidades que oferecem os cursos de BBA é creditada pela Association to Advance Collegiate Schools of Business (2011). 0 curso de BBA é realizado em tempo integral, com duração de 3 a 4 anos, correspondendo, em média, a 180 horas de créditos nas áreas administrativas. Assim, o BBA é um curso abrangente 
em que se estuda os conceitos gerais da administração, dispondo, aind,a de cursos por área específica, tais como:

- Negócios internacionais (FLORIDA INTERNATIONAL UNIVERSITY, 2011);

- Administração (JAMES MADISON UNIVERSITY, 2010);

- Administração - Marketing (GEORGIA STATE UNIVERSITY, 2011);

- Administração - Gestão (BERKELEY COLLEGE [a], 2011);

- Administração - Gestão de Sistemas de Informação (PENNSYLVANIA COLLEGE OF TECHNOLOGY, 2011).

O curso de administração - Gestão na universidade de Berkeley College ([a], 2011) é dividido em três módulos: (1) principal, (2) negócios e (3) artes liberais. No módulo principal, estão às disciplinas de: princípios de gestão; teoria e desenvolvimento organizacional; gerenciando para a mudança; e simulação empresarial. No módulo de negócios, estão às disciplinas de: contabilidade gerencial; seminário de localização; direito empresarial; política e estratégia de negócios; negócios internacionais; gerenciamento de aplicações; e as disciplinas na área de negócios. O terceiro módulo - artes liberais - é constituído das disciplinas: comunicação oral; psicologia; na área de humanidades.

\subsubsection{Estrutura Curricular}

O aluno da Berkeley College não possui uma estrutura estática, podendo cursar as disciplinas aquelas que são de seu maior interesse. No entanto, existem aquelas que possuem pré-requisitos, ou seja, que só podem ser cursadas se outras disciplinas também tiverem sido.

Tabela 1 - Notas no EUA

\begin{tabular}{|c|c|c|c|}
\hline Nota & $\%$ de conhecimento na prova & Explicação & Ponto de notas \\
\hline A & $90-100$ & exelente & 4 \\
\hline$B+$ & $85-89$ & muito bom & 3,5 \\
\hline B & $80-84$ & bom & 3 \\
\hline $\mathrm{C}+$ & $75-79$ & acima da média & 2,5 \\
\hline C & $70-74$ & média & 2 \\
\hline D & $60-69$ & passou & 1 \\
\hline $\mathrm{F}$ & - & reprovado & 0 \\
\hline
\end{tabular}

Fonte: Berkeley College [b] Student Handbook (2011).

O Quadro 2 monstra as matérias que são oferecidas no curso de administração - Gestão e os créditos de cada uma delas. Para a graduação, são necessárias 180 horas/crédito por trimestre. No último trimestre, as disciplinas são oferecidas somente no fim da tarde e início da noite, de modo a não interferir nos estágios.

\begin{tabular}{|l|c|l|c|}
\hline \multicolumn{1}{|c|}{ Disciplinas Principais } & Créditos & \multicolumn{1}{|c|}{ Disciplinas “Artes Liberais” } & Créditos \\
\hline $\begin{array}{l}\text { Fundamentos de Contabilidade } \\
\text { para Gestores }\end{array}$ & 4 & Redação descritiva & 4 \\
\hline Contabilidade Gerencial & 4 & Escrita Através da Literatura & 4 \\
\hline Organização e Gestão de Empresas & 4 & Falar em público & 4 \\
\hline Seminário Gestão de Carreira & 1 & Matemática & 4 \\
\hline Direito Empresarial I & 4 & Estatística I & 4 \\
\hline $\begin{array}{l}\text { Aplicações Informáticas em Negó- } \\
\text { cios }\end{array}$ & 2 & Macroeconomia & 4 \\
\hline
\end{tabular}




\begin{tabular}{|l|c|l|c|}
\hline \multicolumn{1}{|c|}{ Disciplinas Principais } & Créditos & \multicolumn{1}{c|}{ Disciplinas “Artes Liberais” } & Créditos \\
\hline Comunicação em negócio & 4 & Microeconomia & 4 \\
\hline Estratégia Empresarial e Política & 4 & Psicologia & 12 \\
\hline Estágio & 5 & Eletivas Humanidades & 12 \\
\hline Princípios de Finanças I & 4 & Matemática/Ciências Eletivas & 12 \\
\hline Negócios Internacionais & 4 & Sociais Eletivas Ciência & 12 \\
\hline Princípios de Gestão & 4 & Liberal Eletivas Artes & 4 \\
\hline Princípios de Marketing & 4 & $\begin{array}{l}\text { Geral Núcleo de Educação Ciências } \\
\text { Humanas Eletivo }\end{array}$ & 4 \\
\hline Aplicações Informáticas & 4 & $\begin{array}{l}\text { Geral da Educação Matemática/Nú- } \\
\text { cleo de Ciências Eletivas }\end{array}$ & 4 \\
\hline Eletivas de Negócios & 36 & $\begin{array}{l}\text { Geral da Educação Núcleo de Ciên- } \\
\text { cias Sociais Eletivo }\end{array}$ & 4 \\
\hline
\end{tabular}

Quadro 2 - Estrutura curricular administração - Gestão.

Fonte: BERKELEY COLLEGE. Business Administration (2011).

\subsubsection{Avaliação}

As notas dos alunos são representadas por letras; a Tabela 1 evidencia o sistema de notas no Berkeley College ([b], 2011). As notas são multiplicadas pelos créditos das disciplinas. O resultado do trimestre é a soma de todas as disciplinas. A presença na aula é indispensável, sendo fator influenciador na nota. $\mathrm{O}$ aluno pode faltar no máximo sete vezes e, se fizer isso, irá receber nota "I".

Caso o trabalho final seja defendido em público, o aluno irá obter o diploma com a denominação Honors. Para as melhores notas, existem os títulos com ou sem Honors: summa cum laude; magna cum laude; cum laude; e with distinction (WHARTON, 2011).

\subsection{BRASIL}

A educação brasileira encontra-se em fase de crescimento acelerado nos últimos anos (FREITAS; ARICA, 2008), refletindo, dessa forma, na ampliação de Instituições de Ensino Superior (IES). Especificamente quanto ao curso de administração, o número de IES que o oferecem tem aumentado consideravelmente. No Brasil, o curso de administração é oferecido em universidades públicas e privadas. Nas universidades públicas, o curso é disponibilizado em Universidades Federais, Estaduais e Institutos Federais e, nas privadas, em Universidades, Centros de Ensino e Faculdades privadas.

\subsubsection{Exigências para ingressar na universidade}

As Universidades Federais, em sua grande maioria utilizam, o processo SISU - Sistema de Seleção Unificada, que foi desenvolvido pelo Ministério da Educação para selecionar os candidatos às vagas das instituições públicas de ensino superior. A seleção é feita pelo Sistema com base na nota obtida pelo candidato no Exame Nacional de Ensino Médio (Enem). As universidades estaduais ainda utilizam o processo tradicional chamado vestibular, das quais algumas fazem uso parcial da nota do Enem. Para que a universidade faça uso dessa nota, o candidato deve indicar, no formulário de inscrição, seu número de inscrição no Enem para que a universidade possa verificar o resultado do candidato.

O Enem é destinado aos alunos concluintes e egressos do ensino médio e tem como finalidade a avaliação do aluno ao término da escolaridade básica brasileira. A prova é composta de questões objetivas e de uma redação. A parte objetiva é dividida em quatro áreas: linguagens, 
códigos; ciências humanas; ciências da natureza; e matemáticas e suas tecnologias. Cada categoria é constituída de 45 questões de múltiplas escolhas. A realização das provas acontece em dois dias. O Enem despertou o interesse de várias universidades que passaram a utilizá-lo em seus vestibulares (SOARES; PANSANATO, 1999), de forma parcial ou integral (PORTAL BRASIL, 2011).

O processo seletivo "vestibular" é utilizado por faculdades, centros universitários e/ou universidades da rede particular, federais e estaduais de ensino. Sua periodicidade é de duas ou mais vezes por ano. Porém, há instituições que ainda fazem uso de entrevistas ou outros métodos, tais como: grau de escolaridade, histórico escolar e/ou experiência e desempenho profissional. Outra forma de ingresso dos estudantes no Brasil é o regime por cotas, que beneficia estudantes originários de escolas públicas, negros, indígenas e pessoas com deficiência (PORTAL BRASIL, 2011).

\subsubsection{Universidades: tipos de curso e diploma}

Para explicação sobre os tipos de IES e os respectivos diplomas por elas fornecidos, selecionou-se, como exemplo, a FGV/EBAPE - Escola Brasileira de Administração Pública e de Empresas por ser uma pioneira no curso de administração no país.

O curso tem duração de 8 semestres, ou seja, 4 anos. A FGV/EBAPE prepara seus alunos para exercer a profissão tanto em instituições privadas quanto públicas. As áreas estudadas no curso são: Finanças, Marketing, Gestão da Tecnologia e Gestão de Pessoal (FGV/EBAPE, 2011).

O curso é oferecido em dois períodos: o Ciclo Básico de Administração, que ocorre nos dois primeiros anos, abrangendo as disciplinas básicas da administração, e o Profissional, que deve ser realizado nos dois últimos anos do curso. $O$ intuito é disponibilizar aos alunos conhecimentos de áreas específicas, direcionando-os ao mercado. Ao ingressar no sétimo semestre, o aluno deverá optar pela ênfase em administração Pública ou administração de Empresas (FGV) EBAPE, 2011).

Para conclusão do curso, a maioria das universidades exige a apresentação de um trabalho final, oferecendo uma Coordenação de Estágios. Essa Coordenação deve fazer contato com organizações públicas e privadas para realizar a capacitação do aluno. Outro aspecto do curso no Brasil é a Empresa Júnior, onde os estudantes prestam serviços de consultoria à comunidade, oferecendo preços abaixo do mercado. As empresas Juniores fazem uso da infraestrutura da universidade e contam com o auxílio dos professores, realizando a ligação entre teoria e prática.

\subsubsection{Estrutura Curricular}

A estrutura do curso de administração da FGV/EBAPE é constituída de períodos. O curso estrutura esses períodos com base no conhecimento gradual, pois uma matéria complementa a outra, possuindo muitos pré-requisitos. O aluno pode optar por alterar as disciplinas sugeridas nos períodos; no entanto, não é permitido que se faça uma disciplina sem que seu pré-requisito tenha sido cursado. No Quadro 3, é possível observar as disciplinas que compõem os períodos.

\begin{tabular}{|l|c|l|c|}
\hline \multicolumn{1}{|c|}{ Disciplinas - 1o período } & Créditos & \multicolumn{1}{c|}{ Disciplinas - 20 período } & Créditos \\
\hline Tecnologia da Informação & 6 & Cálculo I & 6 \\
\hline Comunicação Empresarial & 4 & Ciência Política & 4 \\
\hline Geometria Analítica & 6 & Comportamento Organizacional & 4 \\
\hline $\begin{array}{l}\text { Introdução à administração de Empre- } \\
\text { sas }\end{array}$ & 4 & Matemática Financeira & 4 \\
\hline Introdução à administração Pública & 4 & Microeconomia & 4 \\
\hline
\end{tabular}




\begin{tabular}{|c|c|c|c|}
\hline Disciplinas - 10 período & Créditos & Disciplinas - 2ㅇ período & Créditos \\
\hline Introdução às Ciências Sociais & 4 & Organização, Sistemas e Métodos & 4 \\
\hline Psicologia Aplicada à administração & 4 & Teoria Geral da administração & 4 \\
\hline Disciplinas - 3o período & Créditos & Disciplinas - 4 período & Créditos \\
\hline Cálculo II & 6 & Administração Estratégica & 4 \\
\hline Cultura e Sociedade & 4 & Álgebra Linear & 6 \\
\hline Estatística I & 6 & $\begin{array}{l}\text { Análise das Demonstrações Con- } \\
\text { tábeis }\end{array}$ & 4 \\
\hline Introdução à Contabilidade & 4 & Atividades Complementares & 4 \\
\hline Introdução ao Direito & 4 & Estatística II & 6 \\
\hline Macroeconomia & 4 & $\begin{array}{l}\text { Gestão pela Qualidade e Melho- } \\
\text { ria de Processos }\end{array}$ & 4 \\
\hline Políticas e Gestão do Meio Ambiente & 4 & Interpretações do Brasil & 4 \\
\hline Disciplinas - 5o período & Créditos & Disciplinas - 60 período & Créditos \\
\hline Administração de Operações & 4 & Administração Financeira II & 4 \\
\hline Administração de Pessoas & 4 & Empreendedorismo & 4 \\
\hline $\begin{array}{l}\text { Administração de Sistemas de Infor- } \\
\text { mação }\end{array}$ & 4 & Estágio Supervisionado II & 5 \\
\hline Administração Financeira I & 4 & Filosofia, Métodos e Ética & 4 \\
\hline Cálculo III & 6 & Logística Empresarial & 4 \\
\hline Estágio Supervisionado I & 5 & Marketing II & 4 \\
\hline Marketing I & 4 & Pesquisa Operacional I & 4 \\
\hline Disciplinas - 70 período & Créditos & Disciplinas - 8 período & Créditos \\
\hline $\begin{array}{l}\text { Administração Orçamentária e Contro- } \\
\text { ladoria }\end{array}$ & 4 & Eletiva III & 4 \\
\hline Eletiva I & 4 & Eletiva IV & 4 \\
\hline Eletiva II & 4 & Estágio Supervisionado IV & 5 \\
\hline Estágio Supervisionado III & 5 & Monografia & 8 \\
\hline Metodologia de Pesquisa & 4 & Negócios Internacionais & 4 \\
\hline $\begin{array}{l}\text { Modelagem e Acompanhamento de } \\
\text { Projetos }\end{array}$ & 4 & $\begin{array}{l}\text { Tópicos Especiais em Adminis- } \\
\text { tração }\end{array}$ & 4 \\
\hline Pesquisa Operacional II & 4 & & \\
\hline
\end{tabular}

Quadro 3. Disciplinas ofertadas por período.

Fonte: FGV/EBAPE - Escola Brasileira de administração Pública e de Empresas (2011).

\subsubsection{A avaliação}

A avaliação, na maioria das vezes, é realizada nas disciplinas de acordo com o plano de ensino utilizado pelo professor. São empregados métodos como: testes, provas, trabalhos escritos, relatórios de atividades, seminários e projetos. As avaliações podem ser feitas individualmente ou em grupo. O que deve ser levado em consideração, na escolha do tipo de avaliação, é o conteúdo exposto. Algumas universidades exigem, ainda, o estágio supervisionado obrigatório, em que o aluno deve se inserir em uma instituição e utilizar conhecimentos que foram apresentados no decorrer do curso; ao final, esse trabalho deve ser apresentado publicamente. Quanto ao sistema de notas, ele varia entre 10 (nota máxima) e 0 (nota mínima), sendo 6 é a nota mínima exigida para passar na disciplina. 


\section{DISCUSSÃO ACERCA DA ESTRUTURA CURRICULAR}

As disciplinas comuns oferecidas pelos cursos dos três países são apresentadas no Quadro 4 com seus respectivos créditos.

\begin{tabular}{|l|c|c|c|c|c|c|}
\hline \multicolumn{1}{|c|}{ Disciplinas } & Alemanha & Crédito & EUA & Crédito & Brasil & Crédito \\
\hline Fundamentos de administração & $\mathrm{x}$ & 12 & $\mathrm{x}$ & 4 & $\mathrm{x}$ & 4 \\
\hline Matemática & $\mathrm{x}$ & 12 & $\mathrm{x}$ & 8 & $\mathrm{x}$ & 4 \\
\hline Contabilidade & $\mathrm{x}$ & 12 & $\mathrm{x}$ & 4 & $\mathrm{x}$ & 4 \\
\hline Informática & $\mathrm{x}$ & 12 & $\mathrm{x}$ & 6 & & \\
\hline Estatística & $\mathrm{x}$ & 24 & $\mathrm{x}$ & 4 & $\mathrm{x}$ & 12 \\
\hline Finanças (Análise de investimento) & $\mathrm{x}$ & 12 & $\mathrm{x}$ & 4 & $\mathrm{x}$ & 8 \\
\hline Direito & $\mathrm{x}$ & 42 & $\mathrm{x}$ & 4 & $\mathrm{x}$ & 8 \\
\hline Economia (macroeconomia e microeconomia) & $\mathrm{x}$ & 42 & $\mathrm{x}$ & 8 & $\mathrm{x}$ & 8 \\
\hline Marketing & $\mathrm{x}$ & 12 & $\mathrm{x}$ & 4 & $\mathrm{x}$ & 8 \\
\hline Logística/cadeia de suprimentos & $\mathrm{x}$ & 12 & & & $\mathrm{x}$ & 4 \\
\hline Recursos Humanos & $\mathrm{x}$ & 12 & & & $\mathrm{x}$ & 4 \\
\hline Controladoria & $\mathrm{x}$ & 12 & & & $\mathrm{x}$ & 4 \\
\hline Pesquisa Operacional & $\mathrm{x}$ & 18 & & & $\mathrm{x}$ & 8 \\
\hline Ciências Sociais & & & $\mathrm{x}$ & 12 & $\mathrm{x}$ & 4 \\
\hline Psicologia & & & $\mathrm{x}$ & 4 & $\mathrm{x}$ & 4 \\
\hline Negócios Internacionais & & & $\mathrm{x}$ & 4 & $\mathrm{x}$ & 4 \\
\hline Estágio & & & $\mathrm{x}$ & 5 & $\mathrm{x}$ & 20 \\
\hline Estratégia empresarial & $\mathrm{x}$ & 12 & $\mathrm{x}$ & 4 & & 4 \\
\hline Comunicação & 246 & & 78 & & 112 \\
\hline Somatório & & & $\mathrm{x}$ & 4 & $\mathrm{x}$ & 4 \\
\hline
\end{tabular}

Quadro 4. Disciplinas comuns entre os cursos e seus respectivos créditos.

Há seis disciplinas comuns presentes nos três cursos; porém, apenas duas delas possuem créditos iguais nos EUA e no Brasil, que são: Fundamentos de administração e Contabilidade, ambas com 4 créditos. As disciplinas de Matemática, Estatística, Direito e Economia são comuns nos três países; entretanto seus créditos são distintos. A maior diferença de créditos entre elas é observada na disciplina de Direito, que na Alemanha é oferecido em 42 créditos, nos EUA em 8 créditos e no Brasil em 4 créditos. Outra disciplina que vale destacar é Estatística, que possuí na Alemanha 24 créditos, nos EUA4 créditos e no Brasil 8 créditos.

Uma peculiaridade do ensino de administração no Brasil é o número de créditos do Estágio supervisionado, que devem ser cursados do quinto ao último período, com 5 créditos por período, totalizando 20 créditos. Nos EUA a exigência é de 5 créditos e na Alemanha é de 12 semanas de estágio, o que equivale a um período (um semestre). É possível constatar que o curso do Brasil apresentou maior ênfase na prática do que os outros dois cursos, o que proporciona maior flexibilidade ao aluno, que poderá analisar criticamente a relação entre teoria e prática e, dessa forma, tornar-se um profissional melhor adaptável frente às adversidades dos ambientes.

As disciplinas exclusivas de cada um dos cursos são:

- Alemanha - Língua estrangeira de negócios, Administração da produção e de equipamentos, Gerência empresarial, Impostos, Ciências bancárias e Seminário de diploma. 
- EUA - Redação descritiva, Escrita através da literatura, Falar em público, Gestão de Carreira, Liberal eletivas Artes e Eletivas de negócios.

- Brasil - Geometria analítica, Comportamento organizacional, Administração pública, Teoria geral da administração, Álgebra linear, Gestão pela qualidade e Melhoria de processos, Políticas e gestão do meio ambiente, Administração de operações, Empreendedorismo, Administração de sistemas de informação, Metodologia de pesquisa, Modelagem e acompanhamento de projetos e Tópicos especiais em administração.

Analisando-se as disciplinas comuns e as exclusivas de cada curso, foi possível observar que nos EUA há destaque para as disciplinas relacionadas à comunicação e à gestão de pessoas. Na Alemanha, o curso possuiu foco nas disciplinas ligadas ao setor financeiro de uma organização. Já no Brasil, não existe uma tendência específica, pois o curso tenta a abranger as mais variadas esferas administrativas, incluindo meio ambiente, pesquisa, projetos, qualidade, dentre outras.

\section{CONSIDERAÇÕES FINAIS}

Foi observado nos três países que cada um deles possui um sistema de seleção distinto. Nos EUA, esta é realizada pelo vestibular e por carta de recomendação; na Alemanha, pelas notas obtidas ao final da Gymnasium e, no Brasil, pelo vestibular, Enem e sistema de cotas.

No Brasil, o título obtido é o de Bacharel em administração; os cursos tecnológicos fornecem, ainda, o diploma de tecnólogo de acordo com CNE/CP 3, de 18 de dezembro de 2002 (CNE/CP3, 2002). Na Alemanha, o sistema é mais especializado, pois há três tipos de universidade - a Universität, a Fachhochschule e a Berufsakademie -, que provêm dois tipos de títulos - o Bachelor of Science e o Bachelor of Arts. Nos EUA, também é possível escolher entre dois modelos de graduação, que são: Bachelor of Business Administration (BBA) e Bachelor of Science in Business Administration. O Bachelor of Science na Alemanha e nos EUA é comparável com o Bacharel em administração, pelo fato de que desenvolvem habilidades de pesquisas, comportam possibilidade de fazer mestrado ou master e de que o conteúdo, embora os horários dos cursos oferecidos sejam diferentes, é similar. Já os demais títulos têm limitações para estudos futuros.

Outra diferença entre os cursos analisados está na duração exigida, que é de de 3 anos (5.400 horas) na Alemanha e de 4 anos (5.000 horas) nos EUA e no Brasil (cerca de 3.200 horas/ aula no Brasil). A influência da carga horária na formação do profissional de administração pode estar relacionada ao tempo que o aluno necessita se dedicar ao estudo, ampliando, assim, seu leque de conhecimentos. Contudo, vale ressaltar que o principal responsável pelo conhecimento adquirido é o próprio estudante, pois cabe a ele, independente da carga horária exigida, o interesse pela aprendizagem e a disponibilidade em dedicar-se a isso.

Verificou-se, ainda, uma ampla variedade de habilitações nos três países. Na Alemanha e nos EUA, existe, por exemplo, administração de mídia e gestão imobiliária. No Brasil, houve a descaracterização do curso, motivo pelo qual muitas habilitações foram criadas. Em 2004, porém, foi definida pelo Conselho Nacional de Educação (por meio do Parecer CES/CNE 023, de 03/02/2005) e aprovada pelo Ministério da Educação (MEC) a qualificação de apenas "Bacharelado em administração". Com essa nova proposta, as instituições que oferecem o curso podem apenas introduzir linhas específicas no projeto pedagógico e não mais alterar o nome do curso (CFA-BA, 2011).

Quanto à estrutura curricular, as universidades procuram adaptarem-se às novas exigências de mercado, buscando adequar-se às necessidades da economia. A estrutura curricular 
na Alemanha oferece maior possibilidade de combinação, possuindo uma ampla variedade de disciplinas que permitem aos alunos escolherem as que desejarem (no entanto, é possível observar maior ênfase das disciplinas obrigatórias na área financeira). Percebe-se que nos EUA o currículo está voltado para a comunicação e as ciências sociais, demonstrando foco na gestão de pessoas. O curso no Brasil preocupa-se principalmente com a prática do aluno, fato esse percebido pelo número de créditos de estágio. Dentre os três cursos, o do Brasil é o que apresenta maior variedade de disciplinas, abrangendo diferentes áreas administrativas. O profissional de administração necessita gerenciar diferentes recursos, sejam eles financeiros, humanos, tecnológicos ou outros. Com isso, é necessário estar preparado para trabalhar com fatores externos e internos à organização, que influenciarão o sucesso de um empreendimento. Por esse motivo é que uma estrutura curricular diversificada poderá proporcionar uma visão mais ampla de cada área administrativa, fornecendo ao administrador uma tomada de decisão mais bem fundamentada. Em comparação à Alemanha, uma vez que não há informações sobre os créditos nos EUA, o curso no Brasil apresenta a maior quantidade de créditos.

As organizações, sejam elas públicas ou privadas, requerem de administradores competências técnicas, interpessoais e transdisciplinares, o que reflete no crescimento dos cursos analisados na Alemanha, nos EUA e no Brasil. Assim, é um desafio para as universidades preparem profissionais que cumpram as exigências de um mercado globalizado. Para isso, são imprescindíveis investimentos em ciência e tecnologia, primando sempre pela qualidade.

\section{REFERÊNCIAS}

ACT. ACT. Disponível em: http://www.act.org. Acesso em: 02 fev. 2011.

ALEMANHA, GRUNDGESETZ. 23 de maio de 1949. Última alteração: 28 de agosto de 2006. Disponível em: http://bundesrecht.juris.de/ bundesrecht/gg/gesamt.pdf. Acesso em: 11 jan. 2011.

BAFÖG. 26 de agosto de 1971, Última alteração: 23 de dezembro de 2007. Lex: Disponível em: http://www.bafoeg.bmbf. de/de/204.php. Legislação Federal. Acesso em: 13 jan. 2011.

ASSOCIATION TO ADVANCE COLLEGIATE SCHOOLS OF BUSINESS. Disponível em: http:// www.aacsb.edu. Acesso em: 20 março 2011.

\footnotetext{
BA Stuttgart. BWL-Handel. Disponível em: $\quad$ http://www.ba-stuttgart.de/ fileadmin/ba/Wirt schaft/Handel/ Studiengangsbeschreibung_Handel_. inklusive_Modulplaene_.pdf. Acesso em: 08 abril 2011.
}

Studieninhalte. Disponível em: http://www.ba-stuttgart.de/3073.0.html. Acesso em: 12 jan. 2011.

BERKELEY COLLEGE. Business Administration. Disponível em: http://berkeleycollege.edu/ bachelors/Business_Administration/INDEX. HTM. Acesso em: 24 fev. 2011.

Student Handbook. Disponível em: http://berkeleycollege.edu/ FormsandPublications/publications/ StudentHandbook.pdf. Acesso em: 24 fev. 2011.

CAMPELO, A. M. Os saberes docentes construídos pelos professores e as práticas de ensino no curso de Administração FCAP/UPE. 2011. 293f. Tese (Doutorado em Educação). Escola de Educação. Universidade Federal de Pernambuco. Recife.

COLLEGE BOARD. About AP. Disponível em: http://www.collegeboard.com/student/ testing/ap/about.html. Acesso em: 22 fev. 2011. 
About the SAT. Disponível em: http:// www.collegeboard.com/student/testing/sat/ about.html. Acesso em: 22 fev. 2011.

CNE/CP3. Resolução CNE/CP3, 18 de dezembro de 2002. Disponível em: <http://portal.mec. gov.br/cne/arquivos/pdf/CP032002.pdf>. Acesso em maio 2011.

CRA-BA. Conselho Regional de Administração daBahia. Históricodos Cursos deAdministração no Brasil. Disponível em: <http://www.cra-ba. org.br/Pagina/58/Historico-dos-Cursos-deAdministracao-no-Brasil.aspx>. Acesso em maio 2011.

ECTS. Was ist ECTS? Disponível em: http:// www.ects.ch/. Acesso em: 30 março 2011.

E-MEC (2011). Instituições de Educação Superior e Cursos Cadastrados. Disponível em: <http://emec.mec.gov.br/>. Acesso em: 20 maio 2011.

FACHHOCHSCHULE FÜRTECHNIK, WIRTSCHAFT UND KULTUR. Studienordnung. Disponível em: www.htwk leipzig.de/fileadmin/ ordnungen/amtliche_bekanntmachungen/ studien_und_pruefungs_ordnungen/Diplom/ Betriebswirtschaft/Studienordnung_BW_D. pdf. Acesso em: 23 março 2012.

FGV/EBAPE-EscolaBrasileiradeAdministração Pública e de Empresas. 2011. Disponível em: <http://ebape.fgv.br/programas/graduacao/ curso>. Acesso em: 15 março 2011.

FH HANNOVER. de 12 de fevereiro de 2007. Besonderer Teil der Prüfungsordnung. Disponível em: http://www.fakultaet4. fhhannover.de/fileadmin/media/doc/f4/ Studium/Bachelor_Studiengaenge/BBA/ pruefungsordnung_bachelor_bba_bis.pdf. Acesso em: 17 jan. 2011.

FH TRIER. Voraussetzungen. 13 de abril de 2007. Disponível em: http://www.fh-trier.de/ index. php?id=4696. Acesso em: 17 jan. 2011.

FLORIDA INTERNATIONAL UNIVERSITY.
International Business Honors Programm. Disponível em: http://business.fiu.edu/ landon/ibhonors.cfm. Acesso em: 18 fev. 2011.

FURB. Edital n. 3. PRÓ-REITORIA DE ENSINO DE GRADUAÇÃO (ENEM). 2006. Disponível em: http://www.furb.br/2005/ arquivos/940641-554446/Edital_PROEN_032006-ENEM.pdf. Acesso em: 08 jan. 2011.

GEORGIA STATE UNIVERSITY. Department of Marketing. Disponível em: http://www. collegeboard.com/student/testing/sat/about. html. Acesso em: 17 fev. 2011.

HU - HUMBOLDT-UNIVERSITÄT, BERLIN. Studienordnung für den Bachelorstuiengang Betriebswirtschaftslehre. 21 de janeiro de 2004. Disponível em: http://www.wiwi. hu-berlin.de/allgemeines/index_html/pa2/ ordnungen/Stobscbwl.pdf. Acesso em: $07 \mathrm{fev}$. 2011.

JAMES MADISON UNIVERSITY. BBA. Disponível em: http://www.jmu.edu/bba/. Acesso em: 21 jan. 2011.

LAKATOS, E. M.; MARCONI, M. de A. Fundamentos de Metodologia Científica. 7. ed. São Paulo: Atlas, 2010.

Ludwig-Maximilans-Universität München. Betriebswirtschaftslehre. Disponível em: $\quad$ http://www.unimuenchen.de/ studium/studienangebot/studiengaenge/ studienfaecher/betriebsw_/bachelor/index. html. Acesso em: 02 abril 2011.

MAURÍCIO, B. M. D. P. Escola de Administração da UFBA: A trajetória de um centro de referência nacional. 2004. 230f. Dissertação (Mestrado em Administração). Escola de Administração. Universidade Federal da Bahia. Salvador.

NCES - National Center for Education Statistics. Disponível em: http://nces.ed.gov/. Acesso em: 15 maio 2011.

OLIVEIRA, F B de; SAUERBRONN, F. F. Trajetória, 
desafios e tendências no ensino superior de administração e administração pública no Brasil: uma breve contribuição. Revista de Administração Pública [online]. 2007, vol.41, n.spe, p. 149-170. Disponível em: http://dx.doi. org/10.1590/S0034-76122007000700009. Acesso em: 29 abril 2011.

PENNSYLVANIA COLLEGE OF TECHNOLOGY. Business Administration. Disponível em: http://www.pct.edu/catalog/majors/BBS. shtml. Acesso em: 19 abril 2011.

PORTAL MEC, 2010. Catálogo Nacional dos Cursos Superiores de Tecnologia. Disponível em: $\quad<$ http://portal.mec.gov.br/index. php? Itemid=719\&id=12352\&option=com _ content\&view=article>. Acesso em: 18 maio 2011.

SOARES, J. F.; KLEBER, A. P. Desempenho dos alunos no ENEM e no vestibular da UFMG. In: I JORNADA LATINO-AMERICANA DE ESTATÍSTICA APLICADA, 1999. São Carlos. Anais... 1999. p. 137-143. Disponível em: http://www.fae.ufmg. br/game/desempenho.pdf. Acesso em: 13 abril. 2011.

UNIVERSITÄT LEIPZIG. Studienordnung für den Bachelorstudiengang Wirtschaftswissenschaften. Disponível em: http://www.wifa.uni-leipzig.de/fileadmin/ user_upload/WIFA-STUDIENDOKUMENTE/ b a chelorstudiengaenge/bsc-wiwi Neufassungll_SO_Anlage_SO_Modul.pdf. Acesso em: 25 maio 2012.

UNIVERSITÄT LEIPZIG. Studium. Disponível em: http://www.wifa.uni-leipzig.de/studium.html. Acesso em: 25 maio 2012.

VERGARA, S. C. Projetos e relatórios de pesquisa em administração. 10. ed. São Paulo: Atlas, 2010.

VESTIBULAR UFSC 2009. Possibilidades para a vida. 2008. Disponível em: http://www. vestibular2009.ufsc.br/resolucao_acoes_ afirmativas.pdf. Acesso em: 20 fev. 2011.
WHARTON, University of Pennsylvania. Handbook 2008. Disponível em: http:// undergrad.wharton.upenn.edu/forms/ handbook_2008.pdf. Acesso em: 17 março. 2011. 